\title{
Radiochemical Determination of Long-Lived Radionuclides in Proton-Irradiated Heavy Metal Targets: Part II Tungsten
}

Zeynep Talip,* Rugard Dressler, Bianca Schacherl, Jean-Christophe David, Christof Vockenhuber, and Dorothea Schumann

Cite This: Anal. Chem. 2021, 93, 10798-10806

Read Online

ACCESS I

Llll Metrics \& More

Article Recommendations

Supporting Information

ABSTRACT: In this study, proton-irradiated tungsten targets, up to 2.6 $\mathrm{GeV}$, were investigated for the purpose of the experimental cross-section measurements. Radiochemical separation methods were applied to isolate the residual long-lived alpha-emitters ${ }^{148} \mathrm{Gd},{ }^{154} \mathrm{Dy}$, and ${ }^{146} \mathrm{Sm}$ and the betaemitters ${ }^{129} \mathrm{I}$ and ${ }^{36} \mathrm{Cl}$ from proton-irradiated tungsten targets. The molecular plating technique has been applied to prepare ${ }^{148} \mathrm{Gd},{ }^{154} \mathrm{Dy}$, and ${ }^{146} \mathrm{Sm}$ samples for alpha-spectrometry. Production cross-sections of ${ }^{129} \mathrm{I}$ and ${ }^{36} \mathrm{Cl}$ were determined by means of accelerator mass spectrometry. The results are compared with theoretical predictions, obtained with the INCL++-ABLA07 codes, showing good agreement for ${ }^{36} \mathrm{Cl}$ and ${ }^{148} \mathrm{Gd}$, while a factor of 4 difference was observed for ${ }^{154} \mathrm{Dy}$, similar to the results obtained for tantalum targets.

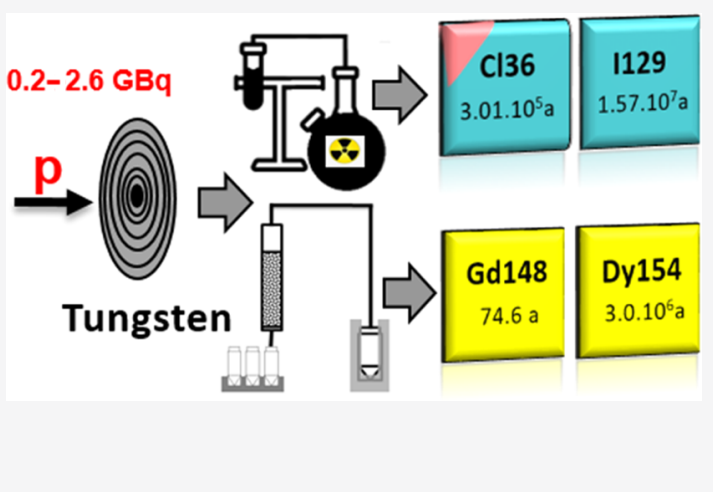

$\mathrm{O}$ ne of the most powerful future neutron spallation sources, the European Spallation Source (ESS), is currently under construction. ${ }^{1}$ Previously, different target materials were considered for ESS, such as $\mathrm{W}, \mathrm{Hg}$, leadbismuth eutectic (LBE), and $\mathrm{Pb}-17 \% \mathrm{Au}$ eutectic. Finally, W was chosen as the best option based on its waste index. ${ }^{2}$

The knowledge of the radionuclide inventory induced during long-term irradiation (up to 5 years) of such a target is a precondition for the risk assessment to ensure a safe operation and storage of disposed target after shutdown as well as to develop emergency scenarios in case of a severe accident. An overview of the radionuclides with half-lives $>10 \mathrm{~h}$ expected to be produced in the ESS target is reported in ref 3 . Besides, ESS recently published a research report focusing on the so-called "difficult-to-measure (DTM) isotopes" in which the radiologically important ESS-specific radionuclides are identified. $^{4}$ According to the evaluations therein, the experimental database on irradiated tungsten spallation target compositions is still insufficient and experimental data are urgently needed to verify existing or future theoretical calculations. The alpha-emitters ${ }^{148 / 150} \mathrm{Gd},{ }^{146} \mathrm{Sm}$, and ${ }^{154} \mathrm{Dy}$ in our case are considered as of essential importance because they impose the highest dose coefficients. ${ }^{5-7}$ These alphaemitting rare earth nuclides contribute $90 \%$ to the total radiotoxicity generated in such a target, with their hazard induced mainly by inhalation and ingestion. They can reach the environment via dust emission or dissolution in the case of contacting the target with water. In addition to severe accident assessments, final disposal strategies need to be considered. Moreover, the isotopes of volatile elements like iodine, chlorine, or cesium comprise a special risk due to their high mobility, enabling them to easily reach the bio- and geosphere. Taking into account their long half-lives, they essentially contribute to the long-term exposure risk of the environment and the population ${ }^{8}$ and are therefore of special interest.

Accurate data on the involved cross-sections comprise one of the numerous mandatory components to be implemented for calculating the production of hazardous radionuclides in thick targets irradiated with high-energy particles. For the target element $\mathrm{W}$, nuclear data on most of these safety-relevant isotopes are either completely missing $\left({ }^{129} \mathrm{I},{ }^{36} \mathrm{Cl},{ }^{154} \mathrm{Dy},{ }^{146} \mathrm{Sm}\right.$, and ${ }^{150} \mathrm{Gd}$ ) or unsure due to experimental uncertainties like for ${ }^{148} \mathrm{Gd} .{ }^{9,10}$ Alpha-spectrometry measurements were performed in these studies without any prior chemical separation of $\mathrm{Gd}$, resulting in high uncertainties because of the self-absorption in the samples and the unknown spatial distribution of the radionuclides therein.

In our previous studies, aimed at the determination of production rates of DTM nuclides in proton-irradiated $\mathrm{Pb}$ and Ta targets, ${ }^{11,12}$ we demonstrated that an essential quality improvement can be achieved by applying prior radiochemical separation. In the present work, we aim to determine the experimental cross-sections of the long-lived alpha-emitters $\left[{ }^{154} \mathrm{Dy}\left(T_{1 / 2}=3.0 \times 10^{6} \mathrm{y}\right),{ }^{13}{ }^{148} \mathrm{Gd}\left(T_{1 / 2}=74.6 \mathrm{y}\right),{ }^{14}\right.$ and

Received: February 10, 2021

Accepted: July 8, 2021

Published: July 28, 2021 
${ }^{146} \mathrm{Sm}\left(T_{1 / 2}=68 \times 10^{6} \mathrm{y}\right)^{15}$ as well as the beta-emitting radionuclides $\left[{ }^{36} \mathrm{Cl}\left(T_{1 / 2}=3.01 \times 10^{5} \mathrm{y}\right){ }^{16}\right.$ and ${ }^{129} \mathrm{I}\left(T_{1 / 2}=\right.$ $\left.1.57 \times 10^{7} \mathrm{y}\right)^{17}$ in proton-irradiated $\mathrm{W}$ targets by applying a prior radiochemical separation of the desired radionuclides to

- obtain values for the ${ }^{148} \mathrm{Gd}$ cross-sections with improved uncertainty in comparison to the values given in refs 9 and 10 ,

- extend the excitation function for ${ }^{148} \mathrm{Gd}$ to proton energies less than $560 \mathrm{MeV}$, and

- measure the cross-sections of ${ }^{154} \mathrm{Dy},{ }^{129} \mathrm{I}$, and ${ }^{36} \mathrm{Cl}$ for the first time.

The results are compared with previous measurements as well as with theoretical calculations performed by a combination of the INCL++ code (Liège intra-nuclear cascade) $)^{18,19}$ and the ABLA07 code (de-excitation phase). ${ }^{20}$

\section{EXPERIMENTAL DETAILS}

Samples. Proton irradiations of $\mathrm{W}$ targets were performed similar to the $\mathrm{Ta}$ and $\mathrm{Pb}$ targets, details of which are described in refs $21-23$ and Table S-1 of the Supporting Information. In total, $11 \mathrm{~W}$ targets (thickness $\sim 125 \mathrm{mg} / \mathrm{cm}^{2}$, a $15 \mathrm{~mm}$ diameter) irradiated with different proton energies (220-2560 $\mathrm{MeV}$ ) were used in this study.

Separation of ${ }^{129} \mathrm{l},{ }^{36} \mathrm{Cl}, \mathrm{W}$, and Lanthanides. Before dissolving the proton-irradiated $\mathrm{W}$ targets, the chemical separation procedure was developed using non-irradiated W foils (Sigma-Aldrich, $\geq 99.9 \%, 0.05 \mathrm{~mm}$ ). The non-irradiated $\sim 250 \mathrm{mg} \mathrm{W}$ foils were dissolved in a solution of $10 \mathrm{M} \mathrm{HNO}_{3}$ and concentrated HF (at a ratio of 2:1). The chemical yields for the separation of $\mathrm{W}$ and lanthanides (Lns) were followed by adding gamma-emitter ${ }^{187} \mathrm{~W}\left(T_{1 / 2}=24.00 \mathrm{~h}\right)^{24}$ and ${ }^{166 \mathrm{~m}} \mathrm{Ho}$ $\left(T_{1 / 2}=1133 \mathrm{y}\right)^{25}$ tracers, respectively. The activity of the ${ }^{166 \mathrm{~m}} \mathrm{Ho}$ tracer was measured before and after distillation to determine the Lns separation yield. A Sigma-Aldrich TraceCERT Tungsten inductively coupled plasma (ICP) standard was used as the target material for the production of ${ }^{187} \mathrm{~W}$ via the ${ }^{186} \mathrm{~W}(n, \gamma){ }^{187} \mathrm{~W}$ nuclear reaction. The tungsten solution (80 $\mu \mathrm{g}$ ) was evaporated in a polyethylene container and irradiated with neutrons using the NAA installation of the spallation neutron source SINQ at the Paul Scherrer Institute ${ }^{26}$ (thermal neutron flux: $0.8 \times 10^{13} \mathrm{~cm}^{-2} \mathrm{~s}^{-1}$, irradiation time: $3 \mathrm{~h},{ }^{187} \mathrm{~W}$ activity: $2 \mathrm{MBq}$ ). The ${ }^{166 \mathrm{~m}} \mathrm{Ho}$ tracer was purchased from Oak Ridge National Laboratory $(\mathrm{kBq}$ amounts of activities were used for the experiments).

Similar to the previous study, $3 \mathrm{mg}$ of iodine as a stable carrier and $5 \mathrm{mg}$ of chlorine were added to the reaction vessel. ${ }^{11}$ After the dissolution of $\mathrm{W}, \mathrm{I}$ and $\mathrm{Cl}$ were distilled into an aqueous hydrazine solution $(1: 1$, total $10 \mathrm{~mL})$ and then precipitated as $\mathrm{AgCl}$ and $\mathrm{AgI}$, respectively. $\mathrm{The}^{129} \mathrm{I} /{ }^{127} \mathrm{I}$ and ${ }^{36} \mathrm{Cl} /{ }^{35} \mathrm{Cl}$ ratios were determined using accelerator mass spectrometry (AMS). Following the distillation process, the remaining solution in the reaction vessel was transferred into a centrifuge tube by adding $7 \mathrm{M} \mathrm{HNO}_{3}$. First, it was centrifuged to separate $\mathrm{H}_{2} \mathrm{WO}_{4}$. Then, $1 \mathrm{~mL}$ of $\mathrm{La}(1 \mathrm{mg}$ of the $\mathrm{La}$ standard for ICP, Fluka Analytical) and $1 \mathrm{~mL}$ of conc. HF were added to the solution to precipitate $\mathrm{LnF}_{3}$. The presence of the ${ }^{187} \mathrm{~W}$ gamma peak $(685.81 \mathrm{keV})$ in the gamma spectrum of the $\mathrm{LnF}_{3}$ precipitate showed the non-complete separation of $\mathrm{W}$. Therefore, before dissolving $\mathrm{LnF}_{3}, 2 \mathrm{~mL}$ of $6 \mathrm{M} \mathrm{NH}_{3}$ (E. Merck) was added to dissolve the remaining $\mathrm{H}_{2} \mathrm{WO}_{4}$. Then, the $\mathrm{LnF}_{3}$ precipitate was dissolved in $1 \mathrm{~mL}$ of $7 \mathrm{M} \mathrm{HNO}_{3}$ and $1 \mathrm{~mL}$ of $0.5 \mathrm{M} \mathrm{H}_{3} \mathrm{BO}_{3}$. After $\mathrm{pH}$ adjustment $(\mathrm{pH} \approx 1$ using 3
$\left.\mathrm{M} \mathrm{NH} \mathrm{H}_{4} \mathrm{OH}\right)$, the gamma-emitting Lns tracers $\left({ }^{166 \mathrm{~m}} \mathrm{Ho}\right.$, ${ }^{159} \mathrm{Dy}$, ${ }^{160} \mathrm{~Tb},{ }^{153} \mathrm{Gd},{ }^{152} \mathrm{Eu},{ }^{145} \mathrm{Sm}$, and ${ }^{145} \mathrm{Pm}$ ) were added to follow the chemical separation and yields. The list of the gammaemitting Lns used for the separation and the determination of the chemical yields are given in Table S-2 in the Supporting Information.

Test Lns separation experiments were performed using Aminex [(HPX87H Bio-Rad, $\mathrm{NH}_{4}{ }^{+}$form, particle size 7-11 $\mu \mathrm{m}$ ) and Sykam (Sykam Chromatographie Vertriebs $\mathrm{GmbH}$, Germany; $\mathrm{NH}^{4+}$ form, particle size $\left.\left.12-22 \mu \mathrm{m}\right)\right]$ cation exchangers. Both separations were performed under the same conditions (column volume: $3.9 \mathrm{~mL}$, flow rate: $0.19 \mathrm{~mL} / \mathrm{min}$ ). Initially, $\alpha$-hydroxyisobutryric acid ( $\alpha$-HIBA) (Sigma-Aldrich 99\%) concentrations were adjusted to obtain the best separation profile for the Aminex resin. Afterward, the same $\alpha$-HIBA concentrations and volumes were used for the Lns separation using the Sykam resin, which allowed us to make a direct comparison of the two resins.

After the test experiments, the same procedure was applied to the proton-irradiated $\mathrm{W}$ targets. To be able to perform blank correction for AMS measurements, between each sample, nonirradiated $\mathrm{W}$ foils (similar to the test experiments) were dissolved together with iodine and chlorine carriers using the same setup and distilled in hydrazine solution. $\mathrm{AgI}$ and $\mathrm{AgCl}$ precipitates obtained from proton-irradiated $\mathrm{W}$ targets and blanks were then dried and transferred to ETH Zurich for AMS measurements.

The Aminex resin was used for the separation of the Lns from proton-irradiated $\mathrm{W}$ targets. After each sample, the resin was rinsed with $4 \mathrm{M} \mathrm{HNO}_{3}$ to elute the remaining cations. Then, it was regenerated using $1 \mathrm{M} \mathrm{NH} \mathrm{NHO}_{3}$. Further separation of the complexing agent from the purified Lns fractions (Dy, Gd, and Sm) was achieved using a TRISKEM LN3 (Triskem International, France, bed volume: $0.8 \mathrm{~mL}$ ) with $1 \mathrm{M} \mathrm{HNO}_{3}$ as an eluent.

Gamma-Ray Spectrometry Measurements. Gamma-ray spectrometry measurements were performed with a Canberra BE2825 broad energy high-purity germanium detector (full width at half-maximum $=0.7 \mathrm{keV}$ at $122 \mathrm{keV}$ ). Gamma-spectra were analyzed with Genie2000 software.

Gamma-ray spectrometry results were used to determine the remaining long-lived gamma-emitting radionuclides in $\mathrm{W}$ targets (before dissolving the targets) to follow online Lns separation (during separation) and to monitor the losses after each separation step (distillation, ion exchange, and molecular plating).

To quantify the chemical yields, after each separation step, the samples were measured using the same container, sample volume, and sample detector distance. The used gammaemitting tracers and their main gamma-lines are listed in Table S-2.

Molecular Plating. After chemical separation of individual Lns fractions, the molecular plating technique was used to prepare thin Dy, Gd, and Sm layers for alpha-spectrometry. Carbon foil (Goodfellow, 99.8\% carbon, $0.075 \mathrm{~mm}$ ) was used as a backing material. More details of the molecular-plating cell can be found in ref 27 .

In our previous studies, we observed a ring-structure distribution of the activity after molecular plating in all the samples. ${ }^{11,12}$ In this study, the anode shape and stirring effects were investigated to improve the homogeneity of the samples, while the other parameters [solvent $=$ iso-propanol $(15 \mathrm{~mL})$, 
$\mathrm{pH}=2.7$, cathode-anode distance $=20 \mathrm{~mm}$, voltage $=300 \mathrm{~V}$, deposition time $=60 \mathrm{~min}]$ were kept as reported in ref 11 .

The effect of the anode geometry was studied using spiralshaped and solid platinum disc anodes (a $2 \mathrm{~cm}$ diameter). Additionally, the plating was performed with and without a stirrer to investigate the stirring effect on homogeneity. The stirrer [ultrasonic stirrer (Fisher Scientific Model 120 Sonic Dismembrator with a $3.1 \mathrm{~mm}$ diameter probe)] was operated at a $30 \%$ power pulse mode to prevent overheating of the solution. After an hour of the plating process, the maximum temperature of the solution was measured as $38{ }^{\circ} \mathrm{C}$.

Radiographic Imaging. The radial activity distribution of the Gd and Dy samples was used to evaluate the homogeneity of the samples. Details of the applied technique are given in refs 12 and 28.

Alpha-Spectrometry Measurements. Alpha-spectrometry measurements were performed using an Alpha Analyst Integrated Alpha Spectrometer (model A-450-21 AM, Canberra) equipped with $450 \mathrm{~mm}^{2}$ PIPS (passivated implanted planar silicon). Energy and efficiency calibrations were performed similar to the procedures described in ref 12 .

The samples were coated with a $30 \pm 2 \mathrm{~nm}$ gold (GoodFellow, 99.95\%) layer using an UNIVEX 450 (Leybold vacuum) thermal evaporation system to avoid the contamination of the semiconductor detectors due to the recoil nuclei sputtering. ${ }^{29,30}$ An example of the ${ }^{148} \mathrm{Gd}$ alpha-spectrum and the background measurement is shown in Figure S-1 (Supporting Information).

AMS Measurements. The ${ }^{129} \mathrm{I} /{ }^{127} \mathrm{I}$ and ${ }^{36} \mathrm{Cl} /{ }^{35} \mathrm{Cl}$ ratio measurements were carried out at ETH Zurich (Laboratory of Ion Beam Physics) using the 0.6 MV TANDY and $6 \mathrm{MV}$ EN TANDEM AMS facilities, respectively. ${ }^{31}$ The AMS measurements were performed using the same settings of the previous study. ${ }^{12}$ In the ion source, negative $\mathrm{I}$ and $\mathrm{Cl}$ ions are extracted from the $\mathrm{AgI}$ and $\mathrm{AgCl}$ samples, respectively. Molecular interferences are removed by the stripping process in the tandem accelerator, and isobaric interferences of ${ }^{36} \mathrm{~S}$ are removed by the gas-filled magnet in the case of ${ }^{36} \mathrm{Cl}$. The radionuclides are counted in a gas ionization detector, whereas the stable isotopes $\left({ }^{127} \mathrm{I}\right.$ and $\left.{ }^{35} \mathrm{Cl}\right)$ are measured in a pulsed mode in a Faraday cup. The measured isotopic ratios are normalized to the internal standards $\mathrm{K} 382 / 4 \mathrm{~N}$ with a nominal ${ }^{36} \mathrm{Cl} /{ }^{\text {nat }} \mathrm{Cl}$ ratio of $(17.36 \pm 0.35) \times 10^{-12}(\mathrm{~K} 3825 / 4 \mathrm{~N})^{31}$ and with a nominal ${ }^{129} \mathrm{I} /{ }^{127} \mathrm{I}$ ratio of $(4.88 \pm 0.10) \times 10^{12}(\mathrm{E} 1) .{ }^{32}$

Uncertainties. The uncertainty budget is given in Table $S$ 3 in Supporting Information. The total uncertainties were calculated by combining individual uncertainty contributions following the recommendation of the guide to the expression of uncertainty in measurement (GUM). ${ }^{33}$

Theoretical Cross-Section Calculations. INCL $++{ }^{18,19}$ and $\mathrm{ABLA} 07^{20}$ codes were used for the theoretical crosssection calculations. In the model, the progenitors were taken into consideration to calculate the cumulative crosssections. $^{12,34}$

\section{RESULTS}

Gamma-Ray Spectrometry Measurements before Separation. Before dissolving the samples, the remaining gamma-emitting radionuclides were determined using gammaray spectrometry. Figure 1 shows the radionuclides detected in proton-irradiated $\mathrm{W}$ targets as a function of proton energy.

Previously, the residual radionuclide production by $72 \mathrm{MeV}$ protons in a W target was studied by Miah et al. ${ }^{35}$ Karamian et

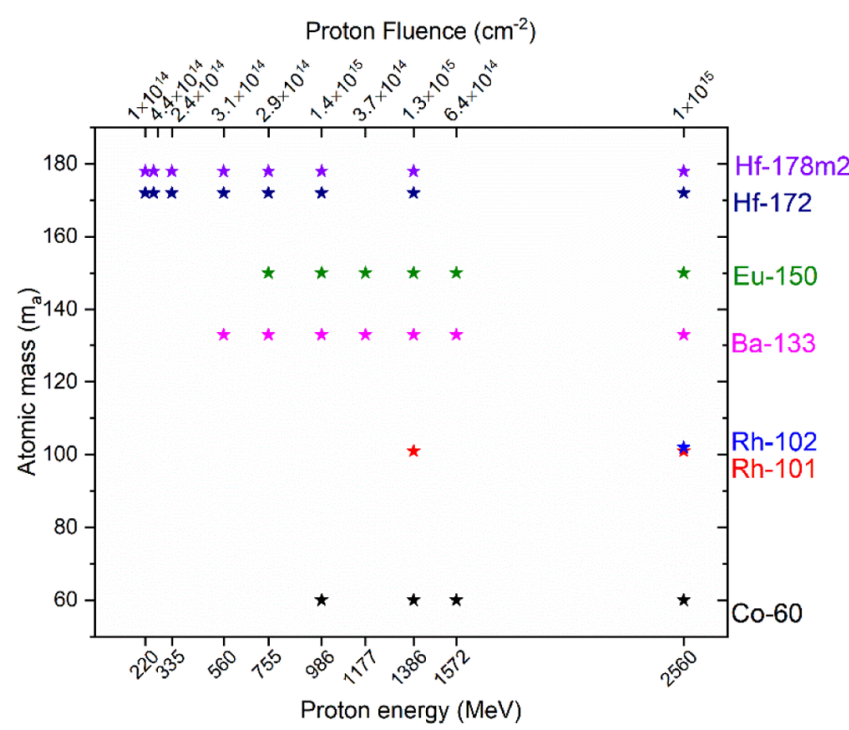

Figure 1. Residual gamma-emitting radionuclides in proton-irradiated $\mathrm{W}$ targets as a function of proton energy.

al. compared the production cross-section of the radionuclides produced in the ${ }^{\text {nat }} \mathrm{W}$ and ${ }^{186} \mathrm{~W}(97 \%)$ targets with protons at 270,420 , and $630 \mathrm{MeV}^{36}$ while the experimental production cross-sections of ${ }^{\text {nat }} \mathrm{W}(\mathrm{p}, \mathrm{x}){ }^{178 \mathrm{~m} 2} \mathrm{Hf},{ }^{172} \mathrm{Hf},{ }^{133} \mathrm{Ba}$, and ${ }^{102} \mathrm{Rh}$ reactions were reported by Titarenko et al. ${ }^{37}$ The available literature data for the production cross-sections of gammaemitting radionuclides $\left(T_{1 / 2}>1.5 \mathrm{y}\right)$ in proton-irradiated $\mathrm{W}$ targets are summarized in Table $S-4$ in the Supporting Information.

Separation of Lns from W. Separation of Lns from proton-irradiated $\mathrm{W}$ was reported for the first time with this study. Gamma-emitter ${ }^{187} \mathrm{~W}$ and ${ }^{166 \mathrm{~m}}$ Ho tracers were added to follow the chemical separation yields. After an additional $\mathrm{H}_{2} \mathrm{WO}_{4}$ separation step, the complete removal of $\mathrm{W}$ was succeeded with an average 91\% Lns separation yield (Table S5 in the Supporting Information). Gamma-ray spectra recorded before and after Lns separation are shown in Figure 2 as an example. The gamma-ray spectrometry measurement of the $\mathrm{LnF}_{3}$ precipitate was performed after dissolving it in $1 \mathrm{~mL}$ of $1 \mathrm{M} \mathrm{HNO}_{3}$ and $1 \mathrm{~mL}$ of $0.5 \mathrm{M} \mathrm{H}_{3} \mathrm{BO}_{3}$.

Fractionation of Dy, Gd, and Sm. To achieve a good Lns separation, it is essential to choose a proper complexing agent. Up to date, a considerable amount of research effort has been expended on the testing of various chelating agents (lactic acid, oxydiacetic acid, iminodiacetic acid, thiodiacetic acid, tetradiacetic acid, nitrilotriacetic acid, etc.) for Lns separation. ${ }^{38,39}$ It was shown in the literature that $\alpha$-HIBA exhibits a consistent trend across the entire Lns series. ${ }^{39-42}$ In the previous studies, a DOWEX cation exchanger- $\alpha$-HIBA separation system was used to separate Lns from proton-irradiated $\mathrm{Pb}$ and $\mathrm{Ta}$ targets. $^{11,12}$

In the present study, to increase the decontamination factor for the individual Lns fractions, Aminex and Sykam cation exchangers ${ }^{43-47}$ were tested under the same experimental conditions. Figure 3 shows the comparison of the separation profiles obtained with Sykam and Aminex resins, respectively. Both resins showed much better resolution compared to the previously used DOWEX cation exchanger. ${ }^{11,12}$ Previously, Höhlein et al., compared Lns separation efficiency for DOWEX (particle size: $37-74 \mu \mathrm{m}$ ) and Aminex cation-exchange resins and reported that the favorable properties of the Aminex resin 


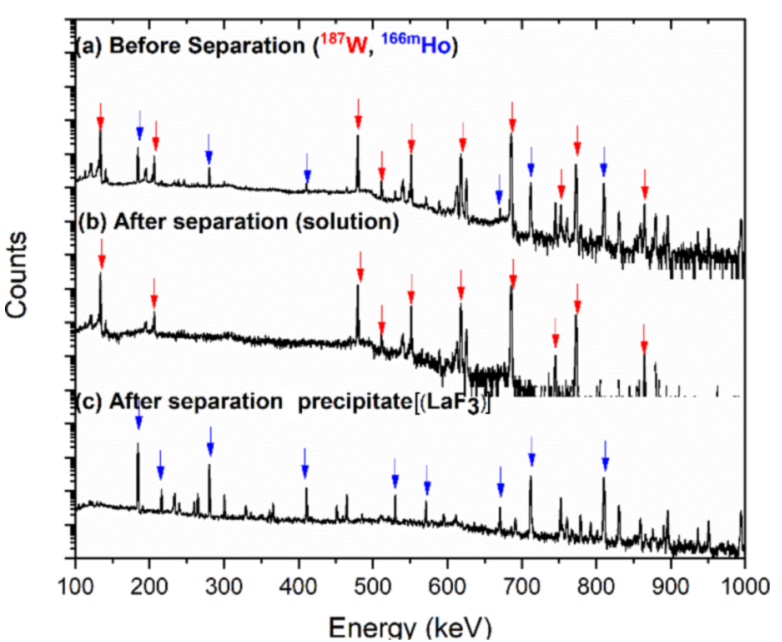

Figure 2. Representative gamma-ray spectra of the $\mathrm{W}$ sample before (a), after Lns separation (solution) (b), and after Lns separation $\left(\mathrm{LnF}_{3}\right)$ (c) (blue and red arrows present gamma-lines of ${ }^{187} \mathrm{~W}$ and ${ }^{166 m} \mathrm{Ho}$, respectively). Spectra a and b were recorded for $1800 \mathrm{~s}$, while c was taken for $24 \mathrm{~h}$ to present the complete removal of ${ }^{187} \mathrm{~W}$.

can be due to its smaller and homogeneous particle distribution. ${ }^{43}$ In the present study, no significant effect was observed due to the smaller particle size of the Aminex resin $(7-11 \mu \mathrm{m})$ compared to the Sykam resin $(12-22 \mu \mathrm{m})$. The tailing effect was, however, more pronounced for the Aminex resin.

In the previous studies, ${ }^{11,12}$ the $\mathrm{LN}$ resin was used to separate the complexing agent (HIBA) from the samples. In the present study, the TRISKEM LN3 resin is preferred. Since it is a weaker extractant compared to the LN resin, ${ }^{48}$ lower nitric acid concentrations and volumes were sufficient to achieve back extraction of Lns.

Molecular Plating. The resolution of the alpha-spectra can be influenced by sample preparation techniques, which means that the sample preparation step has an explicit importance for the alpha-spectrometry measurements. ${ }^{49-52}$ There are three important parameters to be considered: ${ }^{53-55}$

- high counting statistics gained by a high deposition yield to lower the uncertainty,
- low sample thickness to prevent from self-absorption and low-energy tailing, and

- homogeneous activity distribution to optimize the efficiency.

In our previous studies, ${ }^{11,12}$ the first two parameters (a high deposition yield and thin samples) were successfully reached using the molecular plating technique, with insufficient homogeneity. It is known that inhomogeneous activity distribution could affect counting efficiency, resulting in higher uncertainties. $^{56}$ To improve the homogeneity of the sample, the anode shape and stirring effects were investigated as follows.

Geometry of the Anode. Previously obtained lower Gd deposition in the center referred to the used spiral-shaped anode, which could have induced a lower current density in the center resulting in a lower deposition yield of $\mathrm{Gd}$ in this region. ${ }^{12}$ The effect of the anode geometry was studied using solid and spiral platinum disc anodes with a $2 \mathrm{~cm}$ diameter. Klemenčič and Benedik have studied the influence of different anode geometries on the homogeneity of the sample, and they concluded that the spiral and meshed geometries result in the best homogeneities. ${ }^{57}$ In our study, no big difference in the homogeneity of the sample was observed using spiral or solid platinum disk anodes. It indicates that the geometry of the anode has no or very little effect on the homogeneity of the deposited layer under the experimental conditions used in our study.

Stirring Effect. Figure 4 shows the 3D autoradiograph and the diametral activity distribution for a Gd deposited sample. It was observed that the homogeneity of the sample is remarkably improved using an ultrasonic stirrer during the plating process.

As a result, Dy, Gd, and Sm fractions were plated using a spiral shape anode with the presence of an ultrasonic stirrer.

Chemical Yields. The average chemical yields obtained using gamma-ray spectrometry with accordingly adjusted measurement times are 69 and $84 \%$ for Gd and Dy samples, respectively. Individual values are given in Table $S-5$.

Production Cross-Sections for ${ }^{129} \mathrm{I}$ and ${ }^{36} \mathrm{Cl}$. Chant et al. used the $\mathrm{AgCl}$ and $\mathrm{AgI}$ precipitation method, followed by the AMS measurement to measure ${ }^{36} \mathrm{Cl}$ and ${ }^{129} \mathrm{I}$ activities in lichen samples taken from the Chernobyl region. ${ }^{58}$ In this study, similarly, the AMS technique was chosen as a detection
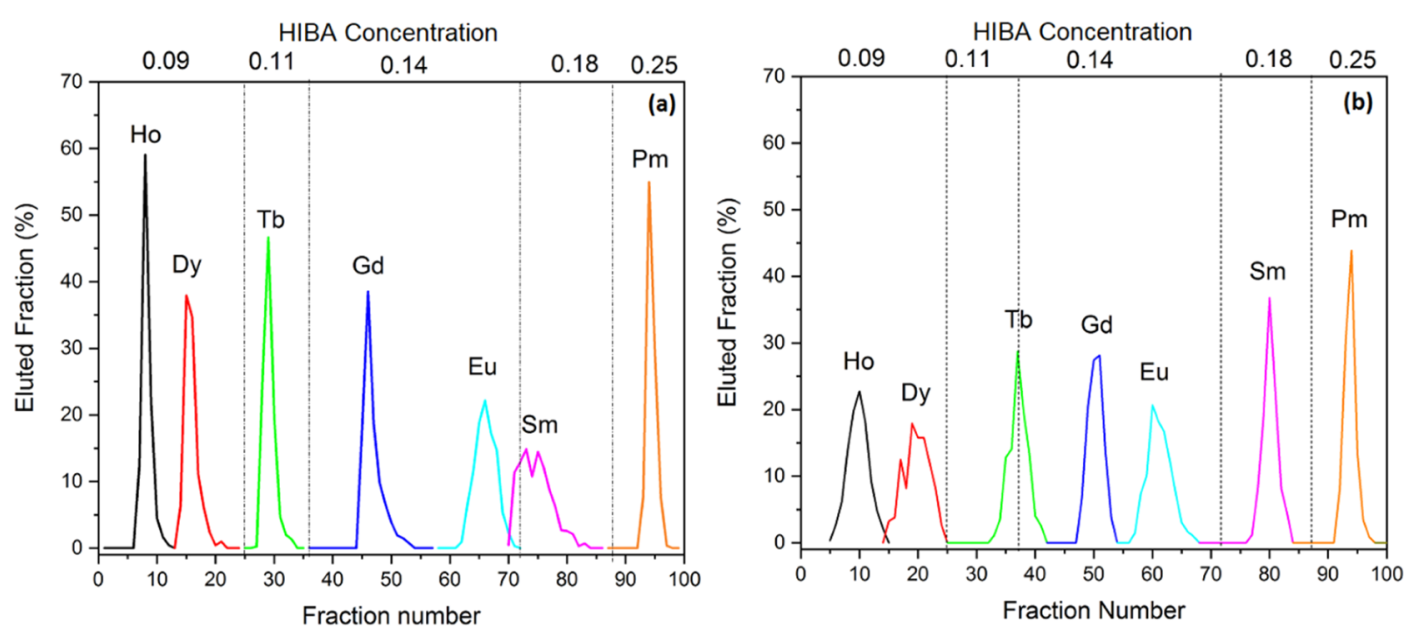

Figure 3. Comparison of the separation profiles of Lns with Aminex (a) and Sykam (b) cation exchangers and the $\alpha$-HIBA separation system with the gradient elution technique. 
(a)
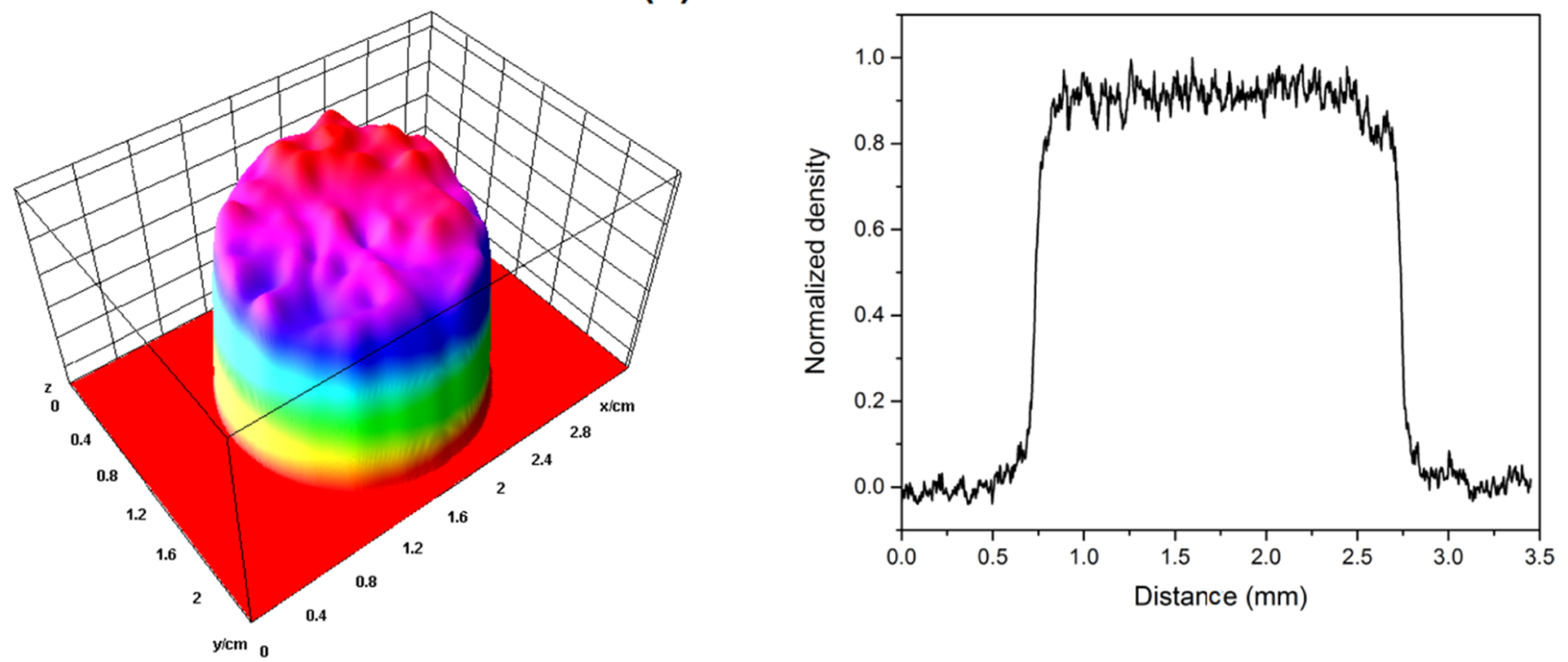

Figure 4. Radiographic imaging $3 \mathrm{D}$ graph (a) and diametral ${ }^{153} \mathrm{Gd}$ activity distribution (b) after molecular plating (with a spiral shape anode and ultrasonic stirrer).

method for ${ }^{129} \mathrm{I}$ and ${ }^{36} \mathrm{Cl}$ in $\mathrm{W}$ targets due to its low detection limits compared to the other techniques such as liquid scintillation counter, ICP-MS, and X- and gamma-ray spectrometry. $^{59}$

The cumulative cross-sections for the ${ }^{129} \mathrm{I}$ and ${ }^{36} \mathrm{Cl}$ production in $\mathrm{W}$ were obtained using ${ }^{129} \mathrm{I} /{ }^{127} \mathrm{I}$ and ${ }^{36} \mathrm{Cl} /{ }^{35} \mathrm{Cl}$ isotopic ratio results (Tables S-6 and S-7 in the Supporting Information) as described earlier in ref 12 .

The experimental cross-section results with the combined standard (i.e., $1 \sigma$ ) uncertainty for the production of ${ }^{129} \mathrm{I}$ and ${ }^{36} \mathrm{Cl}$ in $\mathrm{W}$ targets are given in Table $\mathrm{S}-8$ of the Supporting Information. Figure 5a shows the ${ }^{129} \mathrm{I} /{ }^{127} \mathrm{I}$ isotopic ratios obtained using AMS. Except for the three samples, the ratios were lower than the detection limit. During the irradiation process, iodine can be formed due to fission or spallation. The theoretical calculation shows that the expected iodine

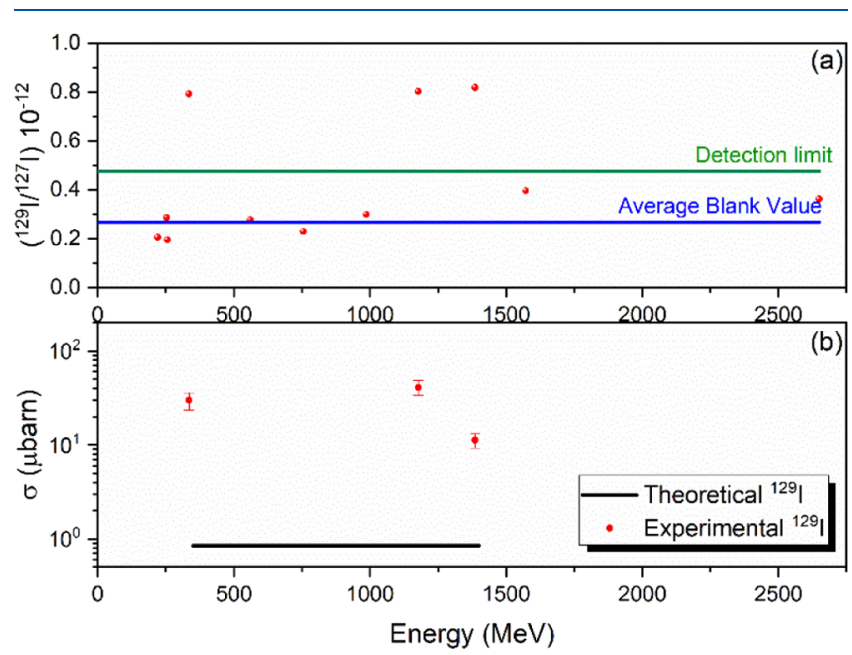

Figure 5. AMS measurement results $\left({ }^{129} \mathrm{I} /{ }^{127} \mathrm{I}\right.$ ratio) without blank correction (a) and experimental and theoretical cross-section results for ${ }^{129} \mathrm{I}$ in proton-irradiated W (b) (detection limit: $0.477 \times 10^{-12}$ and average blank value: $0.267 \times 10^{-12}$ ). production in these processes is very low. Experimental ${ }^{129} \mathrm{I}$ cross-section results obtained in this study for $\mathrm{W}$ targets confirmed the assumption of the theoretical calculations (Figure 5b).

${ }^{36} \mathrm{~S}$ rates, which are a potential interference for ${ }^{36} \mathrm{Cl}$ AMS measurements, were low for all the $\mathrm{AgCl}$ samples. Seven samples, which showed significantly higher values than blanks, were used for the cross-section calculations (see also Table S-7 in the Supporting Information). Comparison of the experimental and theoretical cross-section data showed good agreement for the entire energy range studied (Figure 6). Previously, the cross-sections for the proton-induced production of ${ }^{36} \mathrm{Cl}$ had been reported for different targets such as $\mathrm{Ca}$, $\mathrm{Ti}, \mathrm{Mn}, \mathrm{Fe}, \mathrm{Co}, \mathrm{Ni}^{60}{ }^{60} \mathrm{Ta},{ }^{12} \mathrm{~Pb}, \mathrm{Bi}^{61}$ and $\mathrm{LBE}^{62}$ samples. However, up to date, no experimental data were published for the production of ${ }^{36} \mathrm{Cl}$ in proton-irradiated $\mathrm{W}$ targets.



Figure 6. Comparison of the experimental and theoretical crosssection results for ${ }^{36} \mathrm{Cl}$ in proton-irradiated $\mathrm{W}$. 

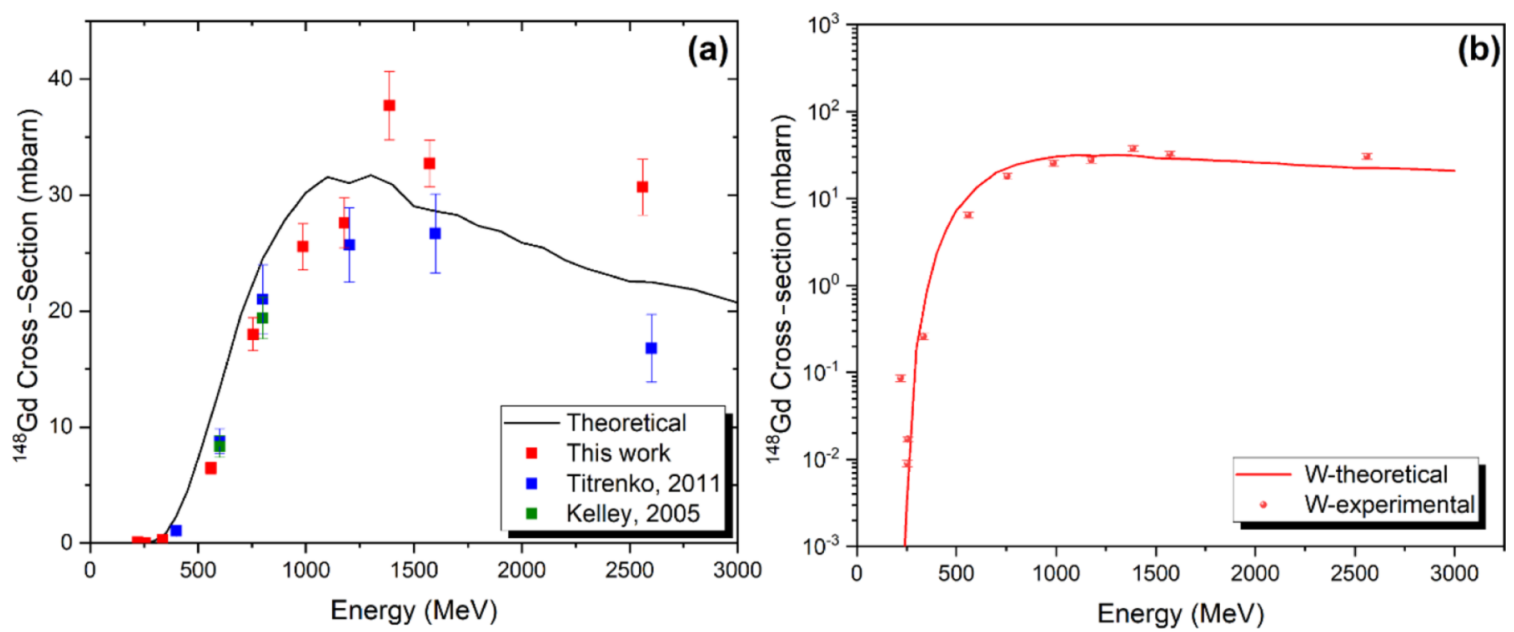

Figure 7. . Comparison of the excitation functions of the production of ${ }^{148} \mathrm{Gd}$ in $\mathrm{W}$ with theoretical and literature data (a) and comparison of the experimental and calculated excitation functions of the production of ${ }^{148} \mathrm{Gd}$ in W (in the logarithmic scale) (b).

Production Cross-Sections for ${ }^{148} \mathrm{Gd}$ and ${ }^{154} \mathrm{Dy}$. The activities of the Dy, Gd, and Sm samples were measured by $\alpha$ spectrometry at a defined solid angle. ${ }^{12}$ No ${ }^{146} \mathrm{Sm}$ peak $\left(E_{\alpha}=\right.$ $2.455 \mathrm{MeV}$ ) could be determined.

Cumulative cross-sections for the production of ${ }^{148} \mathrm{Gd}$ and ${ }^{154} \mathrm{Dy}$ in the $\mathrm{W}(\mathrm{p}, \mathrm{x})^{148} \mathrm{Gd}$ and $\mathrm{W}(\mathrm{p}, \mathrm{x}){ }^{154}$ Dy reactions were calculated with the following equation:

$$
\sigma=\frac{\lambda N \mathrm{e}^{\lambda t_{\mathrm{w}}}}{N_{\mathrm{t}} \phi\left(1-\mathrm{e}^{-\lambda t_{\mathrm{i}}}\right)\left(1-\mathrm{e}^{-\lambda t_{\mathrm{c}}}\right) \varepsilon I Y}
$$

where $\lambda$ is the radionuclide decay constant, $N$ is the number of observed counts, $t_{\mathrm{w}}$ is the time between irradiation and counting, $t_{\mathrm{i}}$ is the irradiation time, $t_{\mathrm{c}}$ is the counting time, $N_{\mathrm{t}}$ is the number of target atoms, $\phi$ is the proton flux, $\varepsilon$ is the detector efficiency, $I$ is the branching ratio, and $Y$ is the total chemical yield.

In Figure $7 \mathrm{a}$, excitation functions for the production of ${ }^{148} \mathrm{Gd}$ in proton-irradiated $\mathrm{W}$ targets are shown in comparison to the available literature data, ${ }^{9,10}$ (see also Table S-9 in the Supporting Information). The theoretical predictions, depicted in Figure $7 \mathrm{a}$, fairly match the low-energy range for all experimental data (with a slight tendency to overestimate). However, they underestimate our new results in the highenergy range and overestimate the former ones provided by Titarenko. ${ }^{10}$ In this study, the uncertainties of the experimental data could be lowered to about $8 \%$ in comparison to the ones given in ref 10 (about 12-15\%). The production cross-section data for proton energies lower than $400 \mathrm{MeV}$ were reported for the first time. A comparison of the experimental results with theoretical values on the ${ }^{148} \mathrm{Gd}$ production in $\mathrm{W}$ targets (Figure 7b) shows good agreement.

Cross-sections for the production of ${ }^{154} \mathrm{Dy}$ in protonirradiated $\mathrm{W}$ targets in the energy range $>500 \mathrm{MeV}$ were determined for the first time (Figure 8, red data points). No ${ }^{154}$ Dy signal $\left(E_{\alpha}=2.872 \mathrm{MeV}\right)$ was detectable for the samples irradiated with protons lower than $500 \mathrm{MeV}$ even after chemical separation due to the very low cross-sections. Comparison of the experimental and theoretical cross-section data of ${ }^{154}$ Dy shows a factor of $\approx 4$ difference similar to our former finding for the Ta targets. In order to compare the results of $\mathrm{Ta}$ and $\mathrm{W}$ targets, the theoretical calculations and experimental results are given in Figure 8. These results make

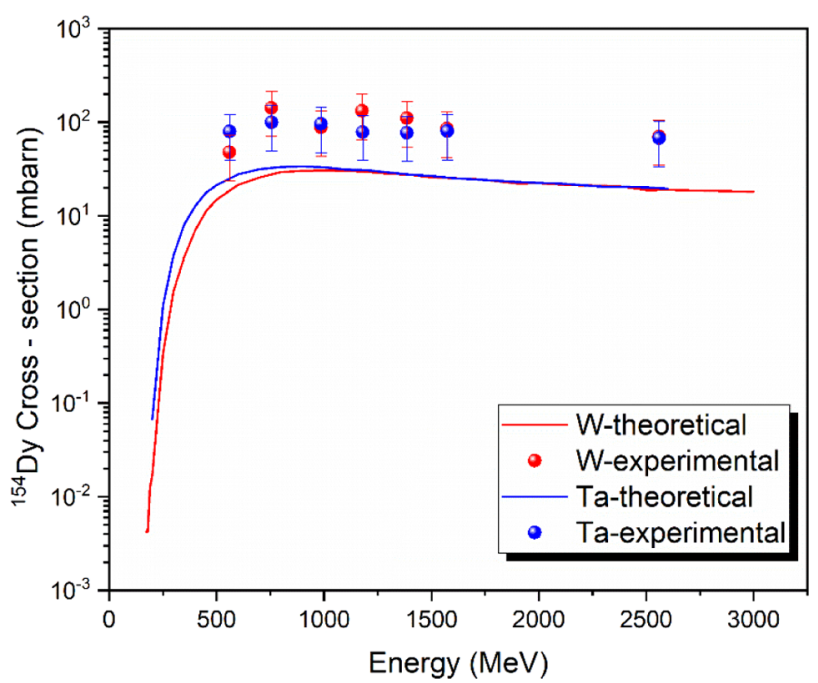

Figure 8. Comparison of the experimental and calculated excitation functions of the production of ${ }^{154} \mathrm{Dy}$ in $\mathrm{Ta}$ (data are taken from ref 12) and $W$ (in the logarithmic scale).

our previous argument stronger regarding the effect of precise ${ }^{154}$ Dy half-life values $\left[T_{1 / 2}:(3 \pm 1.5) \times 10^{6} \mathrm{y}\right]^{13}$ on crosssection measurements. All the experimental and literature data are listed in Table S-9, enabling to recalculate the crosssections $\left(\sigma^{*}\right)$ once a more precise half-life value of ${ }^{154} \mathrm{Dy}$ $\left(T_{1 / 2}^{*}\right)$ will be available

$$
\sigma^{*}=\frac{T_{1 / 2}^{*}}{T_{1 / 2}}
$$

\section{DISCUSSION}

To evaluate the benefit of our approach for measuring DTM radionuclides, we need to look closer into the previous experimental ${ }^{148} \mathrm{Gd}$ cross-section studies, which were performed without prior sample treatment by Kelley et al. ${ }^{9}$ and Titarenko et al. ${ }^{10}$ Due to the strong interaction of $\alpha$-particles with matter, $\alpha$-spectrometry requires a sophisticated sample preparation. High-resolution spectra can be recorded by minimizing the self-absorption, which requires ultrathin layers of the radionuclide to be measured. Kelley et al..$^{9}$ used $3 \mu \mathrm{m}$ 
thick targets and had to face an energy loss of $\alpha$-particles up to 1.7 MeV, resulting in a count distribution from $1.5-3.2 \mathrm{MeV}$. Titarenko et al. ${ }^{10}$ measured samples with thicknesses much larger than the free path (around $4 \mu \mathrm{m}$ ) of $3.2 \mathrm{MeV} \alpha$-particles emitted by ${ }^{148} \mathrm{Gd}$. As a result, the resulting spectrum represents a count rate distribution up to the maximum energy. Moreover, the accompanying $\beta$ - and $\gamma$-radiations emitted by the other reaction products induces high count rates in the low-energy range and interferes with the signal from the $\alpha$ particles. Their contributions were estimated by absorbing the $\alpha$-particles using $\mathrm{Al}$ foil and calculating the losses in the thick targets, thus ending up with uncertainties up to $12 \%$. However, this approach is based on the assumption that the activity is uniformly distributed and the count rate is always proportional to the induced specific activity in the target. These boundary conditions cannot be directly fulfilled. The dissolution of the entire irradiated target and separation of the rare earth fractions, as applied in our method, rule out this problem. Resolutions of less than $40 \mathrm{keV}$ are achievable by this method, ${ }^{11}$ and since $\alpha$-spectrometry in $2 \pi$-geometry is possible with up to $30 \%$ efficiency, also very small amounts of activity can be detected. This enabled us to determine the crosssections for the ${ }^{148} \mathrm{Gd}$ production induced by protons with energies lower than $400 \mathrm{MeV}$ for the first time. Additionally, achieving a better uniformity of the electrodeposited activities as shown in Figure 4 improved the uncertainty of the measurements. The values provided in this study now represent an essential improvement in the database, which is one of the prerequisites for the reliable risk assessment of ESS.

The significance of the results for the radionuclide inventory of the ESS target becomes clear when one considers the recently published report by colleagues from Lund University using the FLUKA code. ${ }^{63}$ They predicted the radionuclide inventory for two scenarios: immediately after 5 years of irradiation and 10 years after shutdown. The authors compare their results with previous theoretical predictions and find a higher total radionuclide production for most of the radionuclides, with a special focus on ${ }^{148} \mathrm{Gd}$, the most toxic radionuclide in the target ${ }^{64}$ and the one showing the biggest differences in the predictions (up to a factor of 7). Accurate cross-section data are only one of the numerous components to be implemented for such calculations. Besides protoninduced reactions, secondary particle-induced reactionsmainly neutron irradiation but also $\alpha$-particles, ${ }^{3} \mathrm{He}$, tritium, etc. and even $\gamma$-radiation have to be considered. Moreover, since in a thick target, all particles with energies from the initial one down to a few $\mathrm{eV}$ are relevant, different models for the different reaction paths have to be taken into account. As discussed in ref 63 , the calculations can yield very different results for the production rates, depending on the applied codes and models and the used nuclear data, with one of them being the cross-section. In view of this, one of the necessary ingredients was provided to improve the calculations. In particular, due to the disagreeing findings in the high-energy range, changes in the results for ${ }^{148} \mathrm{Gd}$ are very likely. This is of special importance for the safety assessments of the facility because the authors of ref 63 obtain with their models already a factor of 7 more ${ }^{148} \mathrm{Gd}$ than other authors.

A simple recalculation of the reaction rates based on our values is, due to the complex nature of the theoretical predictions outlined above, out of the scope of this work. Moreover, a direct evaluation of the impact by recalculating the radionuclide inventory with the improved data might be of limited use as long as not exactly the same entrance parameters, models, and codes are used. Rather, the colleagues from Lund and/or other groups can use the new data-not only for ${ }^{148} \mathrm{Gd}$ but also for the other isotopes studied-to further develop their codes and models and thus improve the quality of their predictions.

Those theoretical predictions of the radionuclide inventory, although being a commonly used and powerful tool in safety assessment, have always to be verified by benchmark experiments. A final proof of the induced radioactivity in the ESS target can only be obtained after taking and analyzing real samples from the target of the working facility, as was done for the MEGAPIE lead-bismuth target. ${ }^{62,65}$ As pointed out by the authors of ref 4 , no reliable sample preparation and analyzing techniques exist so far for the $\alpha$-emitting Lns from irradiated heavy metals like $\mathrm{W}$ or $\mathrm{Ta}$. Such sample preparation procedures must be developed for each target material. With the analysis procedures developed in the present work for $\mathrm{W}$ and in ref 12 for Ta, this gap was fulfilled and the necessary methods were provided.

\section{CONCLUSIONS}

In our previous publications, the results obtained from protonirradiated $\mathrm{Pb}$ and $\mathrm{Ta}$ targets were presented in detail. To conclude our comprehensive study, in this paper, experimental cross-section measurements were performed with protonirradiated $\mathrm{W}$ targets. It is worth mentioning that by being the target of ESS, the results obtained with $\mathrm{W}$ targets will have particular importance.

These publication series have clearly shown the high impact of radiochemistry for improving the accuracy of the crosssection measurements. Lns separation from proton-irradiated $\mathrm{W}$ targets and production cross-sections of the long-lived volatile beta-emitters ${ }^{36} \mathrm{Cl}$ and ${ }^{129} \mathrm{I}$ and the alpha-emitter ${ }^{154} \mathrm{Dy}$ were reported for the first time with this work. Signals of ${ }^{146} \mathrm{Sm}$ and ${ }^{150} \mathrm{Gd}$ could not be detected due to their low concentration and comparably long half-lives. Similar to the results obtained with $\mathrm{Pb}$ and $\mathrm{Ta}$ targets, comparison of the experimental and theoretical cross-section data for ${ }^{148} \mathrm{Gd}$ was in good agreement, while theoretical cross-section data obtained for ${ }^{154}$ Dy were underestimated. As was highlighted in our previous publications, more precise half-life measurements are urgently needed to improve the data quality for cross-section measurements. It is particularly vital for the halflife of ${ }^{154} \mathrm{Dy}$. A corresponding half-life measurement is currently ongoing in the frame of the ERAWAST II project in our laboratory, ${ }^{66}$ and the recently reported preliminary halflife value of ${ }^{154} \mathrm{Dy}(1.18 \pm 0.12 \mathrm{My}){ }^{67}$ showed the accuracy of the experimental excitation function data reported in this study.

\section{ASSOCIATED CONTENT}

\section{SI Supporting Information}

The Supporting Information is available free of charge at https://pubs.acs.org/doi/10.1021/acs.analchem.1c00640.

Description of the W samples; characteristic gammalines of the tracers used for the separation and the determination of the chemical yields; experimental uncertainties for the cross-section measurements; literature data for the cross-sections of ${ }^{178 m 2} \mathrm{Hf},{ }^{172} \mathrm{Hf}$, ${ }^{133} \mathrm{Ba}$, and ${ }^{102 \mathrm{~m}} \mathrm{Rh}$ in proton-irradiated ${ }^{\text {nat }} \mathrm{W}$ targets for different proton energies; chemical separation yields of 
Gd and Dy samples; AMS measurement results for ${ }^{129} \mathrm{l} /{ }^{127} \mathrm{l}$ and ${ }^{36} \mathrm{Cl} /{ }^{35} \mathrm{Cl}$ ratio in proton-irradiated $\mathrm{W}$ targets; experimental cross-section results with the combined standard (i.e., $1 \sigma$ ) uncertainty for the production of ${ }^{129} \mathrm{I},{ }^{36} \mathrm{Cl},{ }^{148} \mathrm{Gd}$, and ${ }^{154} \mathrm{Dy}$ in $\mathrm{W}$ targets; and comparison of the alpha-spectrum of the ${ }^{148} \mathrm{Gd}$ deposited sample and the background measurement (PDF)

\section{AUTHOR INFORMATION}

\section{Corresponding Author}

Zeynep Talip - Center for Radiopharmaceutical Sciences ETH-PSI-USZ, Paul Scherrer Institute, Villigen-PSI 5232, Switzerland; Laboratory of Radiochemistry, Paul Scherrer Institute, Villigen 5232, Switzerland; (1) orcid.org/00000002-5095-799X; Phone: +41-56-310 2486;

Email: zeynep.talip@psi.ch

\section{Authors}

Rugard Dressler - Laboratory of Radiochemistry, Paul Scherrer Institute, Villigen 5232, Switzerland

Bianca Schacherl - Laboratory of Radiochemistry, Paul Scherrer Institute, Villigen 5232, Switzerland; - orcid.org/ 0000-0003-4542-0108

Jean-Christophe David - IRFU, CEA, Université ParisSaclay, Gif-sur-Yvette F-91191, France

Christof Vockenhuber - Laboratory of Ion Beam Physics, ETH Zurich, Zürich 8093, Switzerland

Dorothea Schumann - Laboratory of Radiochemistry, Paul Scherrer Institute, Villigen 5232, Switzerland

Complete contact information is available at:

https://pubs.acs.org/10.1021/acs.analchem.1c00640

\section{Notes}

The authors declare no competing financial interest.

\section{ACKNOWLEDGMENTS}

This project was funded by the Swiss National Science Foundation (SNF grant no. 200021-159738).

\section{REFERENCES}

(1) https://europeanspallationsource.se/ (accessed on Mar 17, 2021).

(2) Kókai, Z.; Török, S.; Zagyvai, P.; Kiselev, D.; Moormann, R.; Börcsök, E.; Zanini, L.; Takibayev, A.; Muhrer, G.; Bevilacqua, R.; Janik, J. Nucl. Instrum. Methods Phys. Res., Sect. B 2018, 416, 1-8.

(3) Barkauskas, V. Review of Radionuclides in ESS, Report BAR-2019/ 02; Lund University, 2019.

(4) Stenström, K. E.; Barkauskas, V.; Pedehontaa-Hiaa, G.; Nilsson, C.; Rääf, C.; Holstein, H.; Mattsson, S.; Martinsson, J.; Jönsson, M.; Bernhardsson, C. Identifying Radiologically Important ESS-specific Radionuclides and Relevant Detection Methods; Technical Report SSM 2020:08; SSM, 2020.

(5) Stankovsky, A.; Saito, M.; Artisyuk, V.; Shmelev, A.; Korovin, Y. J. Nucl. Sci. Technol. 2001, 38, 503-510.

(6) Mora, T.; Sordo, F.; Aguilar, A.; Mena, L.; Mancisidor, M.; Aguilar, J.; Bakedano, G.; Herranz, I.; Luna, P.; Magan, M.; Gonzalezdel Moral, O.; Vivanco, R.; Jimenez-Villacorta, F.; Sjogreen, K.; Oden, U.; Perlado, J. M.; Martinez, J. L.; Bermejo, F. J. J. Nucl. Sci. Technol. 2018, 55, 548-558.

(7) Ene, D.; Avila, R.; Hjerpe, T.; Bugay, D.; Stenberg, K. J. Phys.: Conf. Ser. 2018, 1046, 012018.

(8) Grambow, B. J. Contam. Hydrol. 2008, 102, 180-186.
(9) Kelley, K. C.; Hertel, N. E.; Pitcher, E. J.; Devlin, M.; Mashnik, S. G. Nucl. Phys. A 2005, 760, 225-233.

(10) Titarenko, Y. E.; Batyaev, V. F.; Titarenko, A. Y.; Butko, M. A.; Pavlov, K. V.; Florya, S. N.; Tikhonov, R. S.; Zhivun, V. M.; Ignatyuk, A. V.; Mashnik, S. G.; Leray, S.; Boudard, A.; Cugnon, J.; Mancusi, D.; Yariv, Y.; Nishihara, K.; Matsuda, N.; Kumawat, H.; Mank, G.; Gudowski, W. Phys. At. Nucl. 2011, 74, 573-579.

(11) Talip, Z.; Pfister, S.; Dressler, R.; David, J. C.; Vögele, A.; Vontobel, P.; Michel, R.; Schumann, D. Anal. Chem. 2017, 89, 68616869.

(12) Talip, Z.; Dressler, R.; David, J. C.; Vockenhuber, C.; Müller Gubler, E.; Vögele, A.; Strub, E.; Vontobel, P.; Schumann, D. Anal. Chem. 2017, 89, 13541-13549.

(13) Holden, N. E. Long-Lived Heavy Mass Elements Half-Lives $(A>125)$. BNL-NCS-36960; IUPAC general assembly: Lyon France, 1985; pp 1-19.

(14) Prestwood, R. J.; Curtis, D. B.; Cappis, J. H. Phys. Rev. C 1981, 24, 1346-1347.

(15) Kinoshita, N.; Paul, M.; Kashiv, Y.; Collon, P.; Deibel, C. M.; DiGiovine, B.; Greene, J. P.; Henderson, D. J.; Jiang, C. L.; Marley, S. T.; Nakanishi, T.; Pardo, R. C.; Rehm, K. E.; Robertson, D.; Scott, R.; Schmitt, C.; Tang, X. D.; Vondrasek, R.; Yokoyama, a. Science 2012, $335,1614-1617$.

(16) Nica, N.; Cameron, J.; Singh, B. Nucl. Data Sheets 2012, 113, $1-155$.

(17) Timar, J.; Elekes, Z.; Singh, B. Nucl. Data Sheets 2014, 121, 143-394.

(18) Mancusi, D.; Boudard, A.; Cugnon, J.; David, J.-C.; Kaitaniemi, P.; Leray, S. Phys. Rev. C: Nucl. Phys. 2014, 90, 1-30.

(19) Boudard, A.; Cugnon, J.; David, J.-C.; Leray, S.; Mancusi, D. Phys. Rev. C 2013, 87, 014606-014634.

(20) Kelic, A.; Ricciardi, M. V.; Schmidt, K. ABLA07 - towards a Complete Description of the Decay Channels of a Nuclear System from Spontaneous Fission to Multifragmentation; IAEA: Trieste, Italy, 2008.

(21) Gloris, M. Protonen-Induzierte Restkernproduktion in Schweren Elementen Bei Mittleren Energien Doktor Der Naturwissenschaften; Leibniz University Hannover, 1998.

(22) Michel, R.; Bodemann, R.; Busemann, H.; Daunke, R.; Gloris, M.; Lange, H.-J.; Klug, B.; Krins, A.; Leya, I.; Lüpke, M.; Neumann, S.; Reinhardt, H.; Schnatz-Büttgen, M.; Herpers, U.; Schiekel, T.; Sudbrock, F.; Holmqvist, B.; Condé, H.; Malmborg, P.; Suter, M.; Dittrich-Hannen, B.; Kubik, P.-W.; Synal, H.-A.; Filges, D. Nucl. Instrum. Methods Phys. Res., Sect. B 1997, 129, 153-193.

(23) Gloris, M.; Michel, R.; Sudbrock, F.; Herpers, U.; Malmborg, P.; Holmqvist, B. Nucl. Instrum. Methods Phys. Res., Sect. A 2001, 463, 593-633.

(24) Basunia, M. S. Nucl. Data Sheets 2009, 110, 999-1238.

(25) Nedjadi, Y.; Bailat, C.; Caffari, Y.; Froidevaux, P.; Wastiel, C.; Kivel, N.; Guenther-Leopold, I.; Triscone, G.; Jaquenod, F.; Bochud, F. Appl. Radiat. Isot. 2012, 70, 1990-1996.

(26) https://www.psi.ch/en/nis (accessed on Mar 17, 2021).

(27) Maugeri, E. A.; Heinitz, S.; Dressler, R.; Barbagallo, M.; Kivel, N.; Schumann, D.; Ayranov, M.; Musumarra, A.; Gai, M.; Colonna, N.; Paul, M.; Halfon, S.; Cosentino, L.; Finocchiaro, P.; Pappalardo, A. J. Instrum. 2017, 12, P02016.

(28) Novgorodov, A. F.; Korolev, N. A.; Roesch, F. Appl. Radiat. Isot. 2006, 64, 540-542.

(29) Cosma, C.; Rusu, O. A.; Cosma, V.; Nita, D.; Begy, R. Cs.; Timar Gabor, A.; Astilean, A. Protection of Alpha Spectrometry Detectors Using Thin Formvar Films and Influence on Detection Characteristics. RADECS 2011 Proc; IEEE, 2011; pp 729-733.

(30) Rusu, O. A.; Dreve, S.; Begy, R. C.; Nita, D. C.; Bobos, L. D.; Cosma, C. J. Radioanal. Nucl. Chem. 2011, 290, 241-245.

(31) Christl, M.; Vockenhuber, C.; Kubik, P. W.; Wacker, L.; Lachner, J.; Alfimov, V.; Synal, H.-A. Nucl. Instrum. Methods Phys. Res., Sect. B 2013, 294, 29-38.

(32) Ion Beam Physics, ETH Zurich Annual Report; ETH: Zurich, 2015. 
(33) Joint Committee For Guides In Metrology. Evaluation of Measurement Data - Guide to the Expression of Uncertainty in Measurement. Int. Organ. Stand. Geneva ISBN; JCGM, 2008; Vol. 50 (September); p 134.

(34) David, J.-C. Eur. Phys. J. A 2015, 51, 1-57.

(35) Miah, M. H.; Kuhnhenn, J.; Herpers, U.; Michel, R.; Kubik, P. J. Nucl. Sci. Technol. 2002, 39, 369-372.

(36) Karamian, S.; Adam, J.; Chaloun, P.; Filossofov, D. V.; Henzl, V.; Henzlova, D.; Kalinnikov, V. G.; Korolev, N.; Lebedev, N.; Novgorodov, A. F.; Collins, C. B.; Popescu, I. I.; Ur, C. A. Nucl. Instrum. Methods Phys. Res., Sect. A 2004, 527, 609-623.

(37) Titarenko, Y. E.; Batyaev, V. F.; Titarenko, A. Y.; Butko, M. A.; Pavlov, K. V.; Florya, S. N.; Tikhonov, R. S.; Zhivun, V. M.; Ignatyuk, A. V.; Mashnik, S. G.; Leray, S.; Boudard, A.; Cugnon, J.; Mancusi, D.; Yariv, Y.; Nishihara, K.; Matsuda, N.; Kumawat, H.; Mank, G.; Gudowski, W. Phys. At. Nucl. 2011, 74, 551-572.

(38) Nash, K. L.; Jensen, M. P. Handb. Phys. Chem. Rare Earths 2000, 28, 311-371.

(39) Nash, K. L.; Choppin, G. R. Separation of F Elements; Plenum Press: New York, 1995.

(40) Bear, J. L.; Choppin, G. R.; Quagliano, J. V. J. Inorg. Nucl. Chem. 1963, 25, 513-518.

(41) Pourjavid, M. R.; Norouzi, P.; Ganjali, M. R.; Nemati, A.; Zamani, H. A.; Javaheri, M. Int. J. Electrochem. Sci. 2009, 4, 16501671 .

(42) Raut, N. M.; Jaison, P. G.; Aggarwal, S. K. J. Chromatogr. A 2002, 959, 163-172.

(43) Höhlein, G.; Völler, H.; Weinländer, W. Radiochim. Acta 1969, 11, 172-175.

(44) Elchuk, S.; Cassidy, R. M. Anal. Chem. 1979, 51, 1434-1438.

(45) Iwasaki, K.; Haraguchi, H. Anal. Chim. Acta 1988, 208, 163172.

(46) Dadachova, E.; Mirzadeh, S.; Lambrecht, R. M.; Hetherington,

E. L.; Knapp, F. F. Anal. Chem. 1994, 66, 4272-4277.

(47) Lochny, M.; Odoj, R. J. Radioanal. Nucl. Chem. 1998, 228, 165-169.

(48) Philip Horwitz, E.; McAlister, D. R.; Dietz, M. L. Sep. Sci. Technol. 2006, 41, 2163-2182.

(49) Crespo, M. T. Appl. Radiat. Isot. 2012, 70, 210-215.

(50) Henderson, R. A.; Gostic, J. M.; Burke, J. T.; Fisher, S. E.; Wu, C. Y. Nucl. Instrum. Methods Phys. Res., Sect. A 2011, 655, 66-71.

(51) Vascon, A.; Santi, S.; Isse, A. A.; Reich, T.; Drebert, J.; Christ, H.; Eberhardt, K.; Düllmann, C. E. J. Radioanal. Nucl. Chem. 2014, 299, 1085-1091.

(52) Vascon, A.; Wiehl, N.; Reich, T.; Drebert, J.; Eberhardt, K.; Düllmann, C. E. Nucl. Instrum. Methods Phys. Res., Sect. A 2013, 721, 35-44.

(53) Pommé, S. Metrologia 2015, 52, S73-S85.

(54) Pommé, S. Metrologia 2015, 52, S146-S155.

(55) Sibbens, G.; Pommé, S.; Johansson, L.; Denecke, B. Nucl. Instrum. Methods Phys. Res., Sect. A 2003, 505, 277-281.

(56) Spasova, Y.; Pommé, S.; Benedik, L.; Wätjen, U. Acta Chim. Slov. 2007, 54, 854-858.

(57) Klemenčič, H.; Benedik, L. Appl. Radiat. Isot. 2010, 68, 12471251.

(58) Chant, L. A.; Andrews, H. R.; Cornett, R. J.; Koslowsky, V.; Milton, J. C.; Van Den Berg, G. J.; Verburg, T. G.; Wolterbeek, H. T. Appl. Radiat. Isot. 1996, 47, 933-937.

(59) Hou, X.; Roos, P. Anal. Chim. Acta 2008, 608, 105-139.

(60) Schiekel, T.; Sudbrock, F.; Herpers, U.; Gloris, M.; Leya, I.; Michel, R.; Synal, H.-A.; Suter, M. Nucl. Instrum. Methods Phys. Res., Sect. B 1996, 113, 484-489.

(61) Schumann, D.; David, J.-C. Nucl. Data Sheets 2014, 119, 288291.

(62) Hammer-Rotzler, B.; Neuhausen, J.; Vockenhuber, C.; Boutellier, V.; Wohlmuther, M.; Türler, A.; Schumann, D. Radiochim. Acta 2015, 103, 745-758.

(63) Barkauskas, V.; Stenström, K. Nucl. Instrum. Methods Phys. Res., Sect. B 2020, 471, 24-32.
(64) Rääf, C.; Barkauskas, V.; Eriksson Stenström, K.; Bernhardsson, C.; Pettersson, H. B. L. Sci. Rep. 2020, 10, 21887.

(65) Hammer, B.; Neuhausen, J.; Boutellier, V.; Wohlmuther, M.; Türler, A.; Schumann, D. Anal. Chem. 2015, 87, 5656-5663.

(66) Chiera, N. M.; Talip, Z.; Fankhauser, A.; Schumann, D. PLoS One 2020, 15, No. e0235711.

(67) Chiera, N. M.; Talip, Z.; Dressler, R.; Schumann, D. Half-Life Measurement of ${ }^{154}$ Dy via the "direct method". Lab. Radiochem. Annu. Report; Laboratory of Radiochemistry, 2020; p 23 (https://www.psi. $\mathrm{ch} / \mathrm{en} / \mathrm{lrc} /$ annual-reports) 